\title{
Synaptic Events That Generate Fast Oscillations in Piriform Cortex
}

\author{
Kevin L. Ketchum and Lewis B. Haberly \\ Department of Anatomy and Neuroscience Program, University of Wisconsin, Madison, Wisconsin 53706
}

Prominent, odor-evoked, fast $(40-60 \mathrm{~Hz})$ oscillations have been reported in the olfactory bulb and piriform (primary olfactory) cortex of both awake-behaving and anesthetized animals. The present study used current source-density analysis to examine the origin of the fast oscillations evoked by single weak shocks to afferent fibers. These shock-evoked oscillations closely resemble those evoked by odor. The results revealed that each cycle of the oscillatory field potential was generated by a stereotyped series of membrane currents similar to those previously characterized in the nonoscillatory response to strong afferent fiber shocks. Each cycle began with a strong inward current in layer la identified as an EPSC mediated by afferent fibers in distal apical dendrites of pyramidal cells. This afferent input was followed by a strong inward current in layer Ib identified as an EPSC mediated by intrinsic association fibers in middle apical dendritic segments. These excitatory events were followed by a smaller inward current at the depth of pyramidal cell somata (layers II and superficial III) that may be the depolarizing $\mathrm{Cl}^{-}$-mediated IPSC previously identified in the strongshock response. Based on an analysis of the timing of the EPSCs it was concluded that the weak shock-evoked oscillation is generated in the olfactory bulb and that the resulting periodic activity in afferent fibers drives the oscillation in the piriform cortex. It was further concluded that, as previously demonstrated for strong shock responses, mono- and disynaptic EPSCs within each cycle of the fast oscillation consist of successive waves that propagate from rostral to caudal within the piriform cortex, following the course of the afferent and associational fiber systems. Based on the resemblance of the temporal ordering of EPSCs to the "theta burst" paradigm that effectively induces longterm potentiation, and the repetitive spatial juxtaposition of afferent and association fiber EPSCs in dendrites, it is proposed that the ordering of synaptic events during fast oscillations may be, in part, for the purpose of resetting synaptic efficacies during the learning of olfactory discriminations.

[Key words: piriform cortex, olfactory cortex, cerebral cortex, olfaction, oscillation, current source-density analysis]

\footnotetext{
Nov. 23, 1992; revised Apr. 5, 1993; accepted Apr. 7, 1993.

This work was supported by Grants NS19865 (L.B.H.) and NS08328 (K.L.K.) from NINDS.

Correspondence should be addressed to Lewis B. Haberly, Department of Anatomy and Neuroscience Program, University of Wisconsin, 1300 University Avenue, West Loading Dock, Madison, WI 53706.

Copyright (c) 1993 Society for Neuroscience $0270-6474 / 93 / 133980-06 \$ 05.00 / 0$
}

Odor-induced fast oscillatory activity has been well documented in the olfactory bulb and cortex of a large number of vertebrate species (fish through human) in awake-behaving and anesthetized preparations (Bressler and Freeman, 1980). This oscillatory activity is in the same frequency range $(40-60 \mathrm{~Hz}$ in most mammals) as the oscillations evoked under certain conditions in the visual cortex and other neocortical areas that have been the subject of recent scrutiny (reviewed in Ketchum and $\mathrm{Ha}$ berly, 1991).

The present study took advantage of the precise laminar organization of the circuitry in piriform (primary olfactory) cortex (Fig. 1) (Price, 1973; Luskin and Price, 1983b) to examine the mechanism of generation of fast oscillations using current sourcedensity (CSD) analysis. Previous studies with this technique revealed that a strong shock to afferent fibers evokes an ordered series of EPSCs in different dendritic segments of pyramidal cells (Haberly and Shepherd, 1973; Moyano ct al., 1985; Rodriguez and Haberly, 1989; Ketchum and Haberly, 1993a,b). This sequence includes a monosynaptic EPSC in distalmost apical segments mediated by afferent fibers, and a strong disynaptic EPSC in middle apical segments and weaker disynaptic EPSCs in proximal apical and basal dendrites, all mediated by intrinsic associational (corticocortical) fibers. An important question is whether this spatial and temporal sequence of inputs is an artifact of strong shock stimulation. In response to slow natural odor stimuli, one might expect that the circuit would operate in an asynchronous fashion. The present experiments used CSD analysis to explore the hypothesis (Haberly, 1985) that the 40$60 \mathrm{~Hz}$ oscillation evoked by odors in the olfactory bulb gates afferent input to the piriform cortex so that spatially and temporally ordered sequences of synaptic events can occur in spite of the slow time course of natural stimulation.

Since high resolution CSD analysis requires time locked signals, this study was carried out on fast oscillations evoked by single weak shock stimuli to afferent fihers (Freeman, 1968). With this paradigm, only the first oscillatory cycle is directly evoked by the shock; subsequent cycles are generated by the neuronal circuitry. Similarities in this oscillation to that elicited by odors in frequency, amplitude, and phase shift across the cortical surface (Boudreau and Freeman, 1963; Wooley and Timiras, 1965; Freeman, 1975, 1978) suggest that analysis of the mechanism of generation will provide insight into the operation of the piriform cortex during natural stimulation.

The results have confirmed that the two strongest excitatory inputs to apical dendrites, those mediated by afferent and intrinsic association fiber systems, occur in stereotyped fashion within each oscillatory cycle with spatial and temporal relationships approximating those observed in response to strong 


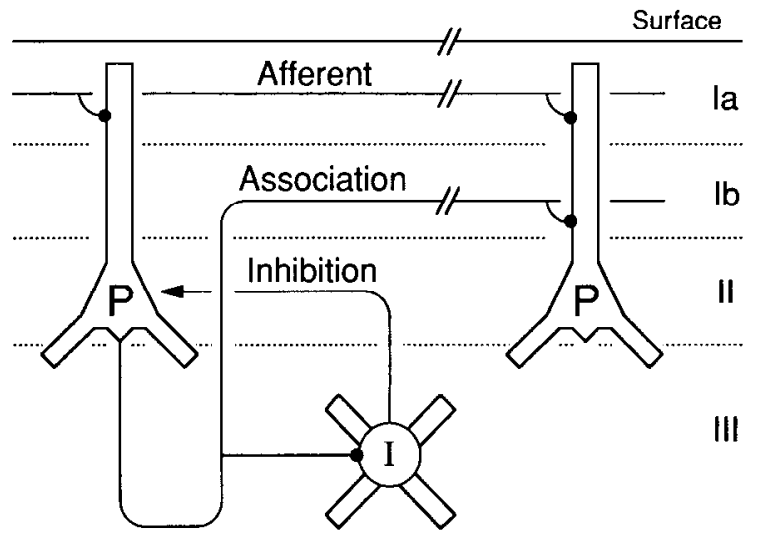

Figure 1. Basic neuronal circuit in piriform cortex (Haberly, 1990). Pyramidal cells $(P)$ with somata concentrated in layer II receive excitatory synapses from afferent fibers that originate in the olfactory bulb and association fibers that originate from other pyramidal cells. Afferent fibers terminate on distal apical dendritic segments in layer Ia; association fibers terminate on more proximal segments of the same pyramidal cells in layer Ib. Both afferent and association fibers are tangentially distributed in layer $\mathrm{I}$. Inhibitory interneurons $(I)$ are excited by pyramidal cells and generate a $\mathrm{Cl}^{-}$-mediated inhibition in the vicinity of cell bodies of pyramidal neurons.

shocks. Based on the relative timing of these EPSCs it is concluded that the weak shock-evoked fast oscillation in piriform cortex is driven by periodic activity in afferent fibers from the olfactory bulb. As a consequence of the tangential distribution of afferent and associational fibers across the surface of piriform cortex, the oscillation recorded at individual points is a consequence of the arrival of two successive "traveling waves" of excitation evoked by afferent, then associational fibers.

These results have been presented, in part, in abstract form (Ketchum and Haberly, 1988).

\section{Materials and Methods}

Adult male rats (200-300 gm) were anesthetized with urethane at 1.4 $\mathrm{gm} / \mathrm{kg}$. Recording and stimulating electrodes were placed under direct vision following surgical exposure of the piriform cortex. Temperature was maintained with a thermostatically controlled warming blanket. Afferent fibers in the lateral olfactory tract (LOT) were stimulated with
0.1 msec duration shocks at $1 \mathrm{~Hz}$. High-strength shocks were $50-75 \%$ of the level evoking maximal response amplitude. Low-strength shock amplitude was adjusted to yield oscillatory responses. The micropipette was advanced with a piezoelectric manipulator equipped with an optical reader head capable of submicrometer accuracy (Burleigh). Field potentials were recorded at $20 \mu \mathrm{m}$ intervals during withdrawal of the micropipette to eliminate cortical dimpling. Correspondence between physiological events and their morphological substrate was established by histological visualization of small dye marks placed at three depths following the completion of recording as previously described (Rodriguez and Haberly, 1989). Four to sixteen responses were averaged on line at each depth; up to 20 sets of data were recorded at single sites for statistical analysis and for averaging to increase the signal-to-noise ratio. Potentials were filtered at $1 \mathrm{kHz}$ and digitized at $2 \mathrm{kHz}$. Interference from ground loops was eliminated by finely manipulating the initiation of trials with a digital circuit that monitors the power line and sequentially places $60 \mathrm{~Hz}$ and its harmonics $180^{\circ}$ out of phase during the averaging of successive trials.

Net transmembrane current, termed current source-density, $I_{m}$, is related to the extracellular field potential, $\phi$, by $I_{m}=-\nabla \sigma \cdot \nabla \phi$, where $\sigma$ is the conductivity tensor (Nicholson and Freeman, 1975). Experimental evidence and theoretical arguments supporting the use of one dimensional CSD analysis (including the absence of a significant conductivity gradient) have been presented for piriform corlex (Rodriguez and Haberly, 1989). Since absolute conductivity has not been measured for piriform cortex, results are presented as the second derivative of potential over depth, which is directly proportional to current sourcedensity. New procedures allowed improved resolution in the analysis of low-amplitude signals. Smoothing and differentiation were done by convolution of the potential over depth with a kernel designed in the spatial frequency domain. The frequency response of the kernel was specified by a super-Gaussian function, $\exp \left[-(n / A)^{4}\right]$, with $n$ the index of spatial frequency and $A$ the $1 / e$ spatial frequency cutoff $(98 \mu \mathrm{m}$ for Fig. 3 and $128 \mu \mathrm{m}$ for Fig. 4). Double differentiation in the spatial frequency domain is equivalent to multiplying the Fourier coefficients by $-(2 \pi n /(N \mathrm{dz}))^{2}$, with $n$ as above, $N$ the total number of terms, and $\mathrm{dz}$ the depth increment. The convolution kernel was derived from the inverse transform of the product of smoothing and differentiating series (multiplication in the spatial frequency domain is equivalent to convolution in the Cartesian domain). Unbiased standard error of the mean was computed from multiple sets of CSD profiles recorded during different penetrations at the same site. Confidence levels were examined as a function of depth or time as in previous studies (Rodriguez and Haberly, 1989; Ketchum and Haberly, 1993a).

\section{Results}

Stimulation of the LOT with a relatively strong shock evoked a triphasic field potential (Fig. $2 A$ ). Successive periods of this
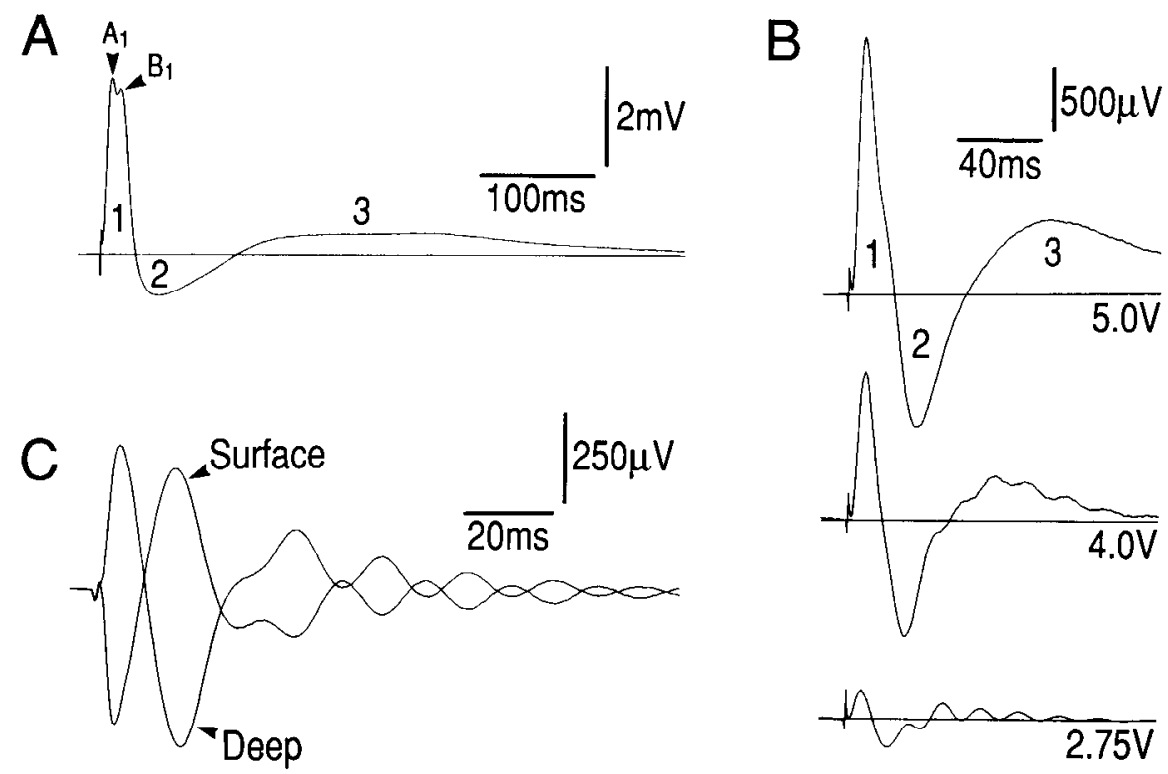

Figure 2. Field potentials recorded in piriform cortex following shock stimulation of afferent fibers in the LOT. $A$, Triphasic field potential evoked by highstrength stimulation. Successive time periods and response components are labeled as described in the Results. $B$, Effects of stimulus strength on field potentials recorded deep in posterior piriform cortex. As stimulus strength was decreased, a long-lasting damped oscillation emerged with a frequency of approximately $55 \mathrm{~Hz}$. C, Superimposed oscillatory field potentials recorded at superficial and deep poles of anterior piriform cortex. Polarity of this response inverted between superficial and deep recording sites, indicating generation within the cortex rather than volume conduction of potential from adjacent areas. 

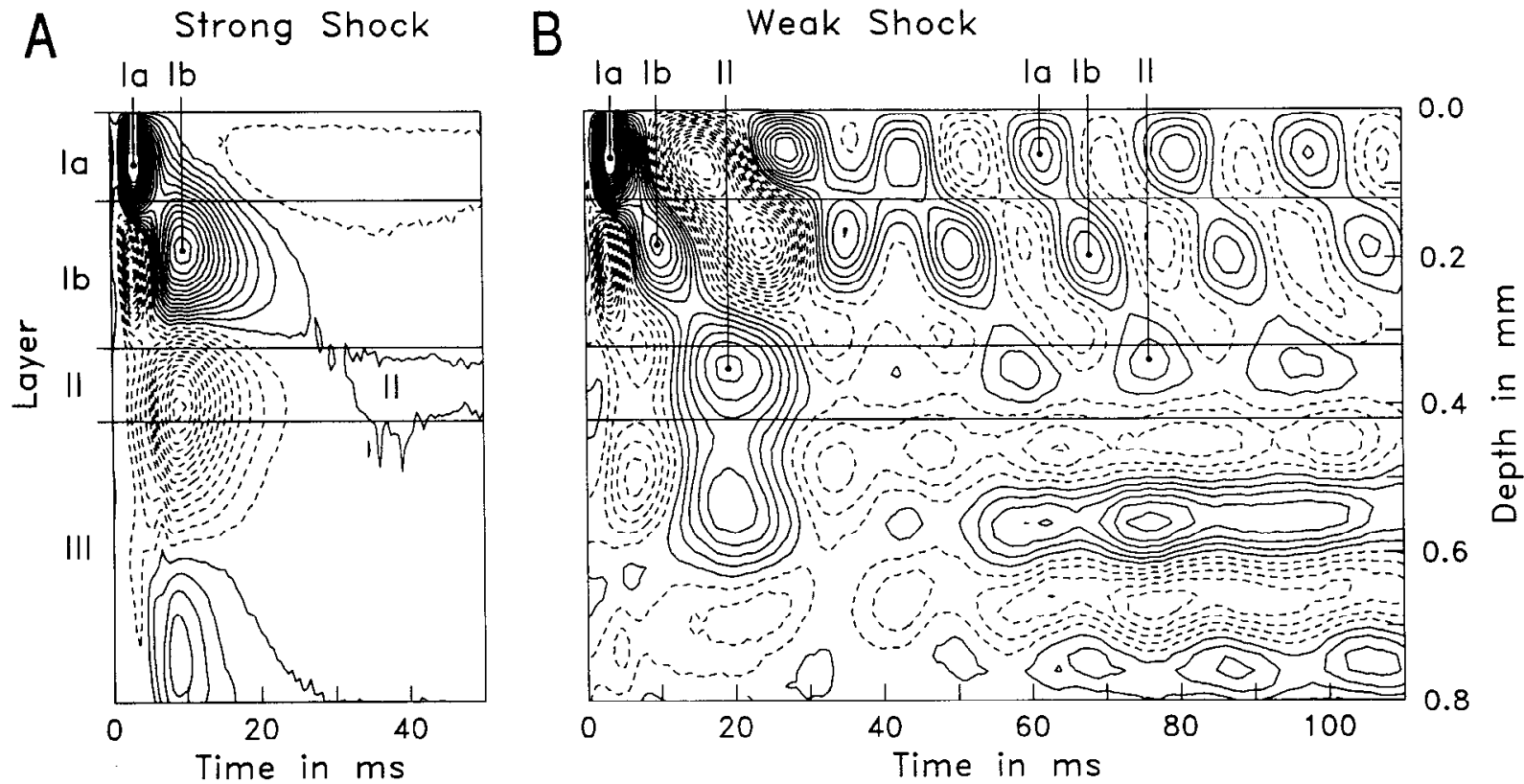

Figure 3. CSD analysis in anterior piriform cortex represented as contour plots. Inward currents (sinks) are represented as solid lines; outward currents (sources), as dashed lines. Sinks are labeled according to layers in which they are maximal. $A$, Response to strong shock stimulation of afferent fibers. Contour interval, $25 \mathrm{mV} / \mathrm{mm}^{2}$; initial Ia sink amplitude, $549 \mathrm{mV} / \mathrm{mm}^{2}$. $B$, Response to single weak shock at same site as in $A$. Contour interval, $2.5 \mathrm{mV} / \mathrm{mm}^{2}$; initial Ia sink amplitude, $62 \mathrm{mV} / \mathrm{mm}^{2}$. Note the stereotyped sequence of sinks in layers Ia, Ib, and II within each oscillatory cycle. The interval between Ia and Ib sinks within each cycle was constant despite variations in the period of initial cycles. Layer II is the compact cell body layer sometimes referred to as layer IIb.

potential have been denoted 1,2 , and 3 ; period 1 has been further divided into $A_{1}$ and $B_{1}$ components (Haberly, 1973). $\Lambda$ s stimulus strength was decreased, this response progressed to a damped oscillatory potential (Fig. 2B,C) as previously described (Freeman, 1962; Woolley et al., 1966). The average frequency of the oscillation was $54 \mathrm{~Hz}$ (Table 1), as compared to $52 \mathrm{~Hz}$ in unanesthetized behaving rats (Bressler and Freeman, 1980).

Nonoscillatory response to strong shocks. CSD analysis of the response to strong afferent fiber shocks revealed the same sequence of membrane currents observed in previous studies in the rat (Ketchum and Haberly, 1993a,b) and opossum (Haberly and Shepherd, 1973; Rodriguez and Haberly, 1989). In these

Table 1. Summary of the timing of membrane currents in layer I derived by CSD analysis in five experiments at anterior, middle, and posterior sites in piriform cortex

\begin{tabular}{llll} 
& & \multicolumn{2}{l}{ Ia to Ib interval $(\mathrm{msec})$} \\
\cline { 3 - 4 } Location & Freq $(\mathrm{Hz})$ & WS & SS \\
Anterior & 54.1 & 7.1 & 6.6 \\
Middle & 56.1 & 7.7 & 9.0 \\
Posterior 1 & 56.5 & 8.1 & 8.7 \\
Posterior 2 & 50.2 & 8.6 & 8.0 \\
Posterior 3 & 55.0 & 9.4 & 9.3 \\
Average & 54.4 & 8.2 & 8.3
\end{tabular}

Frequency of oscillation (Freq) was calculated from the average time between successive peaks of layer Ia sinks (inward currents mediated by afferent fibers) for the first 5 or 6 cycles. The interval between peaks of Ia and Ib sinks (latency of association fiber-mediated component from afferent component) is tabulated for responses to weak and strong shocks (WS and SS, respectively). For oscillatory responses this time is an average for the first 5 or 6 cycles. Note that the average la to Ib interval in strong and weak shock responses is nearly constant (8.2 vs 8.3 msec for five experiments). previous studies it was demonstrated that a series of synaptically mediated events in different dendritic segments and cell bodies of pyramidal cells underlies these currents. The most prominent events during period 1 of the evoked potential are two large EPSCs in apical dendrites that appear as the large inward currents (sinks) labeled $\mathrm{Ia}$ and $\mathrm{Ib}$ in Figures $3 A$ and $4 A$. The initial inward current in layer Ia is monosynaptically mediated in distal dendrites of pyramidal cells. The longer-latency inward current in layer $\mathrm{Ib}$ is mediated in middle apical segments of pyramidal cells throughout the piriform cortex by long association fibers that originate from pyramidal cells confined to the anterior part of piriform cortex. Outward currents (sources) during period 1 consist of an initial peak in layer Ib that abruptly shifts to layer II, followed by a weaker current in layer Ia (dashed lines in Fig. $3 A$ ). It has been demonstrated experimentally and by simulation of this response (Ketchum and Haberly, 1993a,b) that these sources are largely passive return currents associated with the mono- and disynaptic EPSCs.

Currents associated with inhibitory processes during period 2 of the strong shock-evoked field potential are much smaller than those associated with excitatory processes (Ketchum and Haberly, 1993a,b). Inhibition-related currents identified in these earlier studies were the small inward current focused in layer II (pyramidal cell body layer) that first becomes apparent at approximately $30 \mathrm{msec}$ in Figures $3 A$ and $4 A$ ("II") and the associated outward current concentrated in layer I.

Oscillatory response to weak shocks. CSD analysis of the oscillatory response evoked by weak shocks revealed that each cycle was generated by a sequence of membrane currents that resembled those in nonoscillatory responses to strong shocks in both anterior and posterior parts of piriform cortex (Figs. 3, 4). The most striking similarity was the presence of successive inward membrane currents (sinks) in layers Ia and Ib that were 
statistically significant for up to 6 cycles $(p<0.005)$. Based on close parallels with the strong shock response in both depth distribution (compare $A$ and $B$ in Figs. 3 and 4) and relative latency (Table 1), it can be concluded that these inward currents in layers Ia and Ib are EPSCs mediated by cyclical afferent and association fiber activity. The associated sequence of outward currents in layer Ib, layer II, and then layer Ia also paralleled currents identified in strong shock responses.

A consistent observation was that the layer Ib sink was tied in latency to the layer Ia sink in spite of considerable variation in the oscillatory period over the first few cycles. For example, in the experiment illustrated in Figure $3 B$, the interval between the peaks of the layer Ia and layer Ib sinks remained constant within $1 \mathrm{msec}$ when the period of oscillation (interval between successive Ia or Ib peaks) differed by up to $8 \mathrm{msec}$.

Following the two prominent sinks in layer I, a third sink with a peak in layer II or superficial III occurred in each cycle of oscillatory responses in all experiments ("II" in Figs. $3 B$ and $4 B$ ). During the first cycle, the amplitude of this sink approached that of the Ib sink. In subsequent cycles, depth and phase relationships with respect to the Ia and Ib peaks were relatively unchanged, but amplitude was much reduced (Fig. $3 B$ ). A study by Freeman (1968) revealed that unit firing decreases during each phase of the oscillatory field potential associated with this sink, suggesting that it has an inhibitory action. For the first cycle at least, available evidence suggests that this late sink represents the fast, $\mathrm{Cl}^{-}$-mediated IPSC that generates a depolarizing IPSP in cell bodies of superficial pyramidal cells (Scholfield, 1978; Tseng and Haberly, 1988). The latency and time course (Fig. $4 B$ ) are appropriate for the fast IPSP as observed by intracellular recording in vitro (Tseng and Haberly, 1988) and in the present in vivo preparation (Ketchum and Haberly, 1993b). Explorations with the model that successfully reproduced membrane currents and potentials evoked by strong shocks (Ketchum and Haberly, 1993b) revealed that under present conditions of weak stimulation, the same conductance waveform that successfully simulated the action of the $\mathrm{Cl}^{-}$-mediated IPSP in strong shock responses (Fig. 9 in Ketchum and Haberly, 1993b) also reproduced the late inward current in the present study. Small sources and sinks were also present in layer III during the oscillatory responses, but they were not consistent in location between animals and not statistically significant.

\section{Discussion}

Mechanism of generation of fast oscillations. The finding that each oscillatory cycle started with a sharply focused inward current in layer Ia whose depth distribution matched that of the monosynaptic EPSC in strong shock responses (Haberly and Shepherd, 1973; Rodriguez and Haberly, 1989; Ketchum and Haberly, 1993a) suggests that periodic firing of afferents from the olfactory bulb drives the weak shock-evoked fast oscillation in piriform cortex. The consistent delay from this sink to the layer Ib (association fiber-evoked) sink during initial oscillatory cycles when the time between afferent inputs was variable (Table 1, Fig. 3) underscores the dependence of association fiber activity on afferent input. If the oscillation were driven by feedback interactions confined to the piriform cortex, then excitatory activity would be confined to deeper layers (Ib-III) where all intrinsically originating excitatory systems terminate (Price, 1973; Luskin and Price, 1983b). If the afferent fiber activity were triggered by feedback input from the piriform cortex, a constant delay from layer Ib to layer Ia sinks would be predicted rather
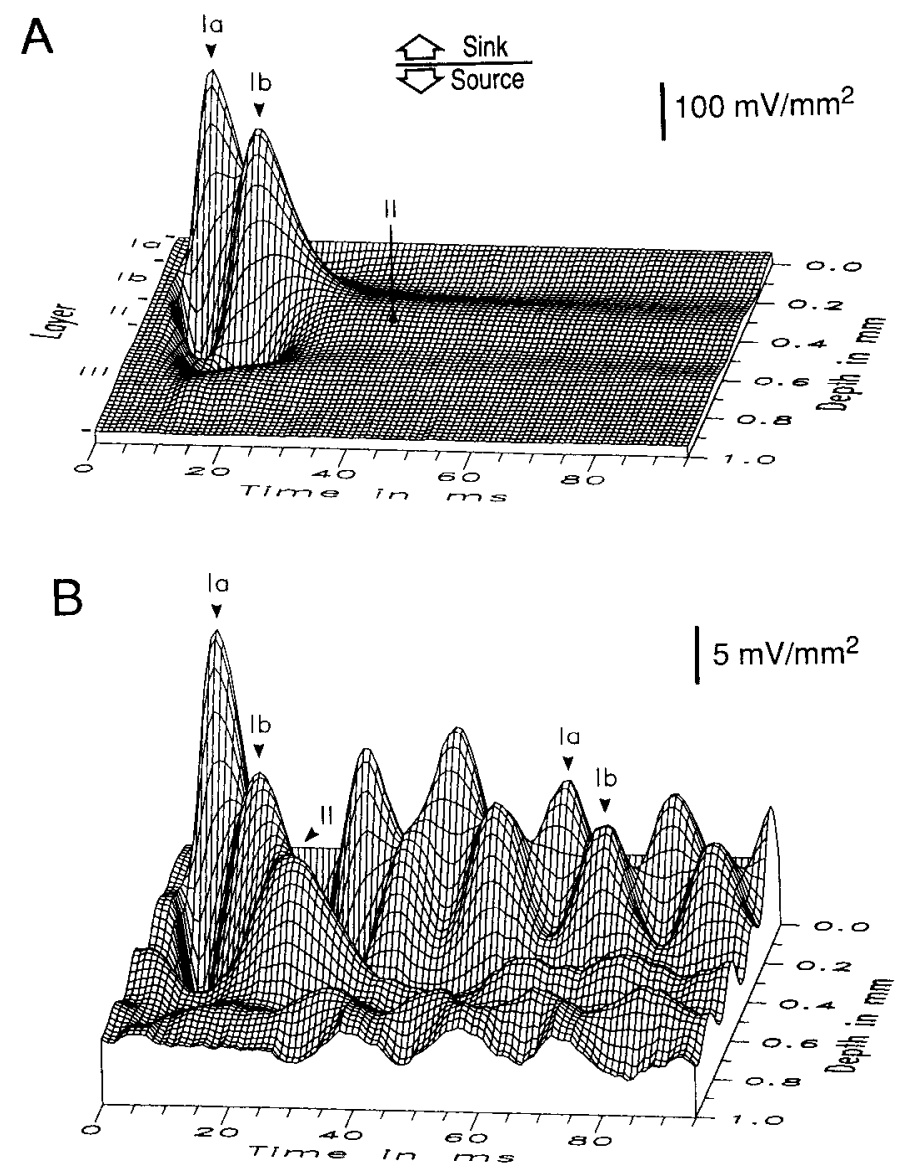

Figure 4. CSD analysis of responses in posterior piriform cortex to strong and weak stimulation of afferent fihers. Upward deflections are proportional to net inward membrane current; downward deflections are proportional to outward current. $A$, Nonoscillatory response to strong stimulation. Sinks that peak in layers Ia, Ib, and II are labeled as in Figure 3. $B$, Oscillatory response to a single low-strength shock at same site as in $A$. Note that the Ia and Ib sinks occurred repetitively within each oscillatory cycle and that their relative amplitudes were similar in the strong shock response and later cycles of the oscillatory response.

than from Ia to Ib as observed. The finding that the latency from layer Ia to Ib sinks in oscillatory responses matches that in nonoscillatory responses to strong shocks (Table 1) where association fiber activity is known to be disynaptically evoked by afferent fiber activity (Ketchum and Haberly, 1993a,b) further supports the conclusion that the weak shock-evoked oscillation is generated within the olfactory bulb rather than within the piriform cortex.

As required for the postulated driving of cortical oscillations by the olfactory bulb, it has been shown that antidromic activation of the olfactory bulb by weak shocks to the LOT evokes damped $40-60 \mathrm{~Hz}$ periodic firing of cells that give rise to the LOT (Freeman, 1972). According to this model, the first cycle of the oscillatory response to weak shocks is directly driven by the shock-evoked volley in LOT axons, but subsequent cycles are driven by oscillatory activity that originates in the olfactory bulb. Evidence suggesting that the olfactory bulb also drives the cortex during oscillatory responses to odor includes the finding that the bulbar oscillator can be activated by odors (Adrian, 1942, 1950), the concomitant occurrence of bulbar and cortical oscillations of the same frequency (Boudreau, 1964; Bressler and Freeman, 1980), and the observation that odor-induced 
cortical oscillations propagate across the surface with a direction and velocity consistent with mediation by afferent fibers (Boudreau and Freeman, 1963). It is important to point out, however, that the present results do not rule out the possibility that under other conditions fast oscillations in the piriform cortex are intrinsically generated as suggested by modeling studies (Freeman 1986; Wilson and Bower, 1992). This caution is reinforced by a report that oscillations can occur in piriform cortex without detectable oscillations in the olfactory bulb, although much less frequently than those occurring together in both structures (Bressler and Freeman, 1980). Evidence has been presented that centrifugal projections originating in the piriform cortex and other areas can modulate the frequency and amplitude of oscillations generated in the olfactory bulb (Gray and Skinner, 1988). However, studies in which the pathways between the olfactory bulb and piriform cortex were blocked by cooling indicate that these projections are not required for bulbar oscillation (Gray and Skinner, 1988).

An important conclusion is that, in addition to the initial afferent input to distal apical dendrites in layer Ia, each cycle contains an excitatory input to more proximal apical segments in layer Ib that results from activity in intrinsic association fibers. In response to strong afferent fiber shocks, inhibition is of sufficient amplitude and duration that association fiber-mediated components are blocked in responses to subsequent shocks for 100 msec or longer (Rodriguez and Haberly, 1989; Ketchum and Haberly, 1993a). The present results reveal that at physiological stimulation levels, the effective duration of inhibition is decreased so that afferent volleys occurring at $20 \mathrm{msec}$ intervals can each evoke disynaptic excitatory components. The constancy in relative amplitude of afferent and association fibermediated components over a broad absolute range (Fig. 4) implies a high degree of linearity in the coupling between afferent input and the output of the pyramidal cell population that generates the disynaptic response.

Waves of postsynaptic activity underlie oscillations. Experimental and modeling studies of responses evoked by strong shocks have revealed that both the monosynaptic EPSC mediated by afferent fibers and the strong disynaptic EPSC mediated by the anteriorally originating association fiber system propagate from rostral to caudal across the piriform cortex (Ketchum and Haberly, 1993a,b). Since the mean velocities of these fiber systems are closely matched, the peaks of the resulting propagating waves of postsynaptic activity occur at a relatively fixed temporal relationship at all points in the cortex. The present finding that the same constant temporal relationship between layer Ia and layer Ib sinks also exists within fast oscillatory cycles in both anterior and posterior parts of the piriform cortex indicates that during $40-60 \mathrm{~Hz}$ oscillations, both of these events also take the form of "traveling waves."

Functional implications. The oscillatory modulation of synaptic activity would appear to allow this circuit to operate in a highly ordered fashion in spite of the asynchronous firing of receptor cells. Such ordered operation could play a role in both integrative processes and synaptic plasticity. Based on the findings from a recent modeling study (Ketchum and Haberly, 1993b), it is likely that successively arriving afferent and association fiber-mediated EPSPs are integrated within each oscillatory cycle. The presence of phasically occurring IPSPs, as suggested by the late currents in the cell body layer, could serve to limit these associative interactions to comparatively narrow, recurring time windows. As a result of the broad spectrum in conduction velocities in both afferent and association fiber systems (Ketchum and Haberly, 1993a,b), and their spatially distributed projection patterns (Haberly and Price, 1977; Luskin and Price, 1983a), activity originating from widespread areas of the olfactory bulb and piriform cortex over a rather broad range of times could converge within each fast oscillatory cycle at given locations in the cortex. Concentration of activity in this fashion could contribute to the analysis of both spatial and temporal components of the olfactory code (Haberly, 1985; Ketchum and Haberly, 1991; Haberly et al., 1993).

Oscillatory modulation could also play a role in activity-induced synaptic plasticity. Rats sniff at the theta frequency (approximately $5 \mathrm{~Hz}$ ) while carrying out olfactory discrimination tasks (Macrides et al., 1982; Eichenbaum et al., 1991) and approximately 7 fast oscillatory cycles occur in the field potential in piriform cortex during each sniff cycle (Woolley and Timiras, 1965). This patterning of activity is reminiscent of the "theta burst" paradigm (Larson et al., 1986) where brief, high-frequency trains of shock stimuli are repeated at the theta frequency. This paradigm has been shown to be effective in inducing long-term potentiation (LTP) in both afferent and association fiber systems in piriform cortex (Jung et al., 1990; Kanter and Haberly, 1990). The present finding that EPSCs in afferent and association systems occur within each oscillatory cycle indicates that both of these systems are activated in a fashion that could facilitate the induction of LTP. Furthermore, the repetitive pairing of afferent and association activity within each oscillatory cycle could contribute to the occurrence of "Hebbian" associative plasticity (see Brown et al., 1990). Associative LTP has been recently demonstrated in piriform cortex by pairing single weak shocks to onc cxcitatory pathway (afferent or association) with each train of a theta burst stimulus to the other pathway (Kanter and Haberly, 1993). A repetitive pairing during natural stimulation should be at least as effective as this less extensive pairing.

Relationship to other systems. Studies in visual, auditory, somatic sensory, motor, and "association" areas of neocortex have revealed $40-60 \mathrm{~Hz}$ oscillatory activity that is evoked by sensory stimuli and accompanies specific behaviors (reviewed in Ketchum and Haberly, 1991; see also Ghose and Freeman, 1992). As in the olfactory bulb, there is oscillatory activity in the same frequency range in thalamic nuclei corresponding to visual, somatic sensory, and parietal association areas. In parietal association and auditory cortex there is evidence suggesting that thalamic oscillations may be causally related to cortical oscillations as postulated for the olfactory bulb and cortex. Oscillations in the parietal association cortex and corresponding thalamic nucleus are coherent and a lesion in the thalamic nucleus results in the disappearance of most of the cortical oscillation (Bouyer et al., 1981). Study by magnetic imaging, although at an early stage, has provided evidence that auditory-evoked 40 $\mathrm{Hz}$ oscillations in the thalamus of human subjects exhibit a phase lead relative to those in cortex (Ribary et al., 1991).

As previously discussed (Ketchum and Haberly, 1991), for there to be an ordering of afferent and intrinsically generated activity within fast oscillatory cycles in the neocortex like that observed in olfactory cortex, neocortical oscillations would have to occur synchronously across areas receiving common thalamic input rather than sequentially as in the piriform cortex. This is because thalamic input arrives with relative synchrony in the neocortex rather than propagating across the surface. Studies in the visual cortex (Eckhorn et al., 1988; Gray et al., 1989; Engel 
et al., 1992) and serisum unotor cortex (Murthy and Fetz, 1992) suggest that such widespread synchrony can occur.

As a consequence of parallels in the morphology, physiology, and neurochemistry of the neuronal circuitry in piriform cortex and neocortex (Haberly, 1990), continued study of the fast oscillations in piriform cortex may assist in understanding the role of oscillations in neocortical areas where architectural complexities make the analysis of dendritic processes difficult with existing methods.

\section{References}

Adrian ED (1942) Olfactory reactions in the brain of the hedgehog. J Physiol (Lond) 100:459-473.

Adrian ED (1950) The electrical activity of the mammalian olfactory bulb. Electroencephalogr Clin Neurophysiol 2:377-388.

Boudreau JC (1964) Computer analysis of electrical activity in the olfactory system of the cat. Nature 201:155-158.

Boudreau JC, Freeman WJ (1963) Spectral analysis of electrical activity in the prepyriform cortex of the cat. Exp Neurol 8:423-439.

Bouyer JJ, Montaron MF, Rougeul A (1981) Fast fronto-parietal rhythms during combined focused attentive behaviour and immobility in cat: cortical and thalamic localizations. Electroencephalogr Clin Neurophysiol 51:244-252.

Bressler SL, Freeman WJ (1980) Frequency analysis of olfactory system EEG in cat, rabbit, and rat. Electroencephalogr Clin Neurophysiol 50:19-24.

Brown TH, Kairiss EW, Keenan CL (1990) Hebbian synapses: biophysical mechanisms and algorithms. Annu Rev Neurosci 13:475511.

Eckhorn R, Bauer R, Jordan W, Brosch M, Kruse W, Munk M, Reitboeck $H J$ (1988) Coherent oscillations: a mechanism of feature linking in the visual cortex? Biol Cybern 60:121-130.

Eichenbaum H, Otto TA, Wible CG, Piper JM (1991) Building a model of the hippocampus in olfaction and memory. In: Olfaction as a model system for computational neuroscience (Davis J, Eichenbaum $\mathrm{H}$, eds), pp 70-100. Cambridge, MA: MIT Press.

Engel AK, Konig P, Kreiter AK, Schillen TB, Singer W (1992) Temporal coding in the visual cortex: new vistas on integration in the nervous system. Trends Neurosci 15:218-226.

Freeman WJ (1962) Alterations in prepyriform evoked potential in relation to stimulus intensity. Exp Neurol 6:70-84.

Freeman WJ (1968) Relations between unit activity and evoked potentials in prepyriform cortex of cats. J Neurophysiol 31:337-348.

Freeman WJ (1972) Measurement of oscillatory responses to electrical stimulation in olfactory bulb of cat. J Neurophysiol 55:762-779.

Freeman WJ (1975) Mass action in the nervous system. New York: Academic.

Freeman WJ (1978) Spatial properties of an EEG event in the olfactory bulb and cortex. Electroencephalogr Clin Neurophysiol 44:586-605.

Freeman WJ (1986) Petit mal seizure spikes in olfactory bulb and cortex caused by runaway inhibition after exhaustion of excitation. Brain Res Rev 1 1:259-284.

Ghose GM, Freeman RD (1992) Oscillatory discharge in the visual system: does it have a functional role? J Neurophysiol 68:1558-1574.

Gray CM, Skinner JE (1988) Centrifugal regulation of neuronal activity in the olfactory bulb of the waking rabbit as revealed by reversible cryogenic blockade. Exp Brain Res 69:378-386.

Gray CM, Konig P, Engel AK, Singer W (1989) Oscillatory responses in cat visual cortex exhibit inter-columnar synchronization which reflects global stimulus properties. Nature 338:334-337.

Haberly LB (1973) Summed potentials evoked in opossum prepyriform cortex. J Neurophysiol 36:775-788.

Haberly LB (1985) Neuronal circuitry in olfactory cortex: anatomy and functional implications. Chem Sens 10:219-238.

Haberly LB (1990) Olfactory cortex. In: Synaptic organization of the brain (Shepherd GM, ed), pp 317-345. New York: Oxford UP.

Haberly LB, Price JL (1977) The axonal projection patterns of the mitral and tufted cells of the olfactory bulb in the rat. Brain Res 129: 152-157.
Haberly LB, Shepherd GM (1973) Current-density analysis of opossum prepyriform cortex. J Neurophysiol 36:789-802.

Haberly LB, Ketchum KL, Kanter ED (1993) LTP in piriform cortex: characterization and functional speculations. In: Current issues in long-term potentiation (Davis J, Baudry M, eds), in press. Cambridge, MA: MIT Press.

Jung MW, Larson J, Lynch G (1990) Long-term potentiation of monosynaptic EPSPs in rat piriform cortex in vitro. Synapse 6:279-283.

Kanter ED, Haberly LB (1990) NMDA-dependent induction of longterm potentiation in afferent and association fiber systems of piriform cortex in vitro. Brain Res 5:175-179.

Kanter ED, Haberly LB (1993) Associative long-term potentiation in piriform cortex slices requires GABA blockade. J Neurosci, in press.

Ketchum KL, Haberly LB (1988) CSD analysis of oscillatory responses in rat piriform cortex reveals sterentyped cyclical components mediated by afferent and intrinsic association fibers. Soc Neurosci Abstr 14:1188.

Ketchum KL, Haberly LB (1991) Fast oscillations and dispersive propagation in olfactory cortex and other cortical areas: a functional hypothesis. In: Olfaction as a model system for computational neuroscience (Davis J, Eichenbaum H, eds), pp 70-100. Cambridge, MA: MIT Press.

Ketchum KL, Haberly LB (1993a) Membrane currents evoked by afferent fiber stimulation in rat piriform cortex. I. Current sourcedensity analysis. J Neurophysiol 69:248-260.

Ketchum KL, Haberly LB (1993b) Membrane currents evoked by afferent fiber stimulation in rat piriform cortex. II. Analysis with a system model. J Neurophysiol 69:261-281.

Larson J, Wong D, Lynch G (1986) Patterned stimulation at the theta frequency is optimal for inducing long term potentiation. Brain Res 368:347-350.

Luskin MB, Price JL (1983a) The topographic organization of associational fibers of the olfactory system in the rat, including centrifugal fibers to the olfactory bulb. J Comp Neurol 216:264-291.

Luskin MB, Price JL (1983b) The laminar distribution of intracortical fibers originating in the olfactory cortex of the rat. J Comp Neurol 216:292-302.

Macrides F, Eichenbaum HB, Forbes WB (1982) Temporal relationship between sniffing and the limbic theta rhythm during odor discrimination reversal learning. J Neurosci 2:1705-1717.

Moyano HF, Cinelli AR, Molina JC (1985) Current generators and properties of early components evoked in rat olfactory cortex. Brain Res Bull 15:237-248.

Murthy VN, Fetz EE (1992) Coherent 25- to $35-\mathrm{Hz}$ oscillation is the sensorimotor cortex of awake behaving monkeys. Proc Natl Acad Sci USA 89:5670-5674.

Nicholson C, Freeman JA (1975) Theory of current source density analysis and determination of conductivity tensor for anuran cerebellum. J Neurophysiol 38:356-368.

Price JL (1973) An autoradiographic study of complementary laminar patterns of termination of afferent fibers to the olfactory cortex. J Comp Neurol 150:87-108

Ribary U, Ioannides AA, Singh KD, Hasson R, Bolton JPR, Lado F, Mogilner A, Llinas R (1991) Magnetic field tomography of coherent thalamocortical $40-\mathrm{Hz}$ oscillations in humans. Proc Natl Acad Sci USA 88:11037-11041.

Rodriguez R, Haberly LB (1989) Analysis of synaptic events in the opossum piriform cortex with improved current source density techniques. J Neurophysiol 61:702-718.

Scholficld CN (1978) A depolarizing inhibitory potential in neurons of the olfactory cortex in vitro. J Physiol (Lond) 275:547-557.

Tseng GF, Haberly LB (1988) Characterization of synaptically mediated fast and slow inhibitory processes in piriform cortex in an in vitro slice preparation. J Neurophysiol 59:1352-1376.

Wilson M, Bower J (1992) Cortical oscillations and temporal interactions in a computer simulation of piriform cortex. J Neurophysiol 67:981-995.

Woolley DE, Timiras PS (1965) Prepyriform electrical activity in the rat during high altitude exposure. Electroencephalogr Clin Neurophysiol 18:680-690.

Woolley DE, Barron BA, Timiras PS (1966) Spectral components in prepyriform electrical activity and changes at high altitude. Electroencephalogr Clin Neurophysiol 20:175-180. 